The Wondrous Woo

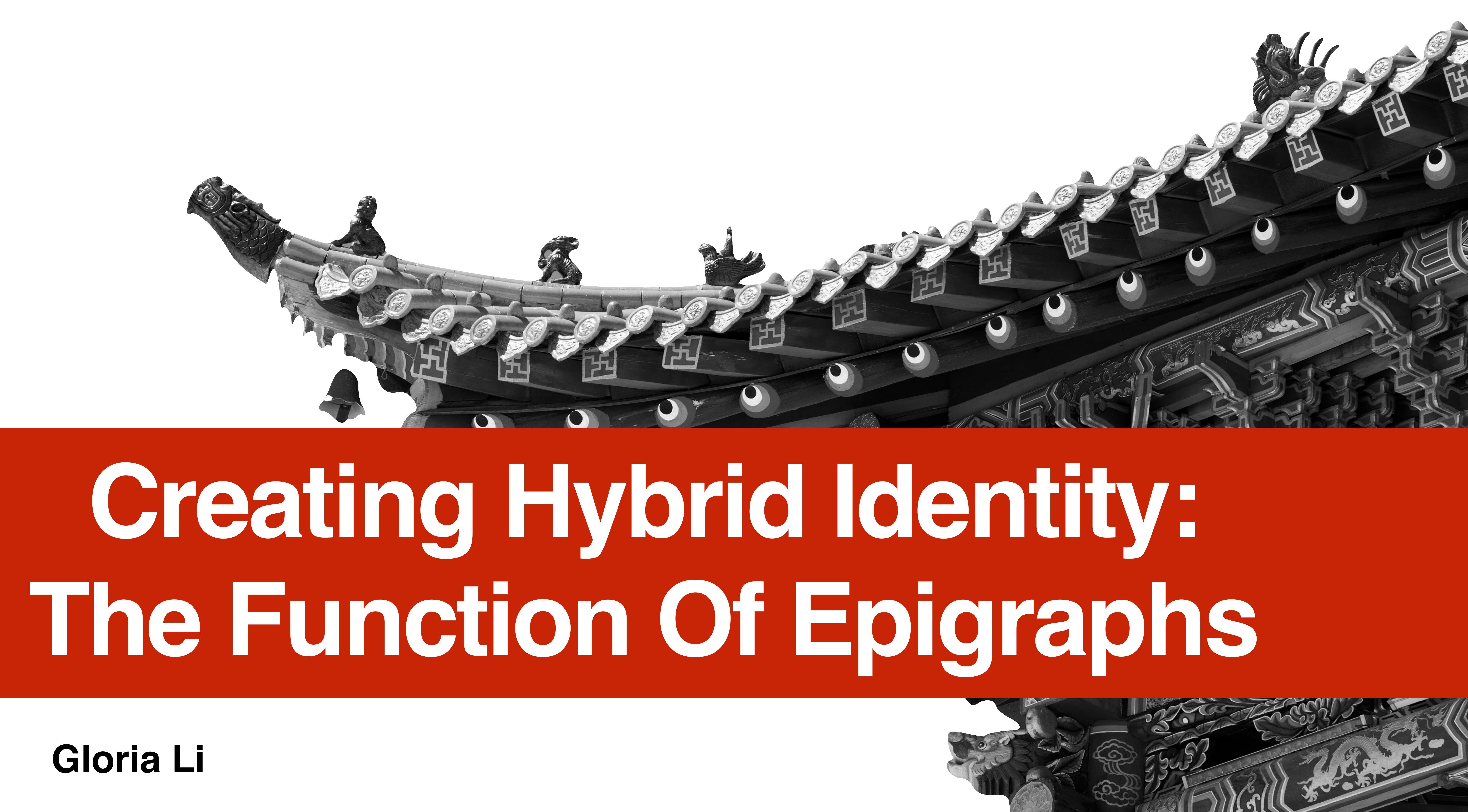




\section{Oxford English Dictionary}

Epigraph: A short quotation or sentence placed at the commencement of a work, a chapter, etc. to indicate the leading idea or sentiment; a motto. 


\section{Thesis Statement}

The epigraphs perform as a structural framework that capture the essence of Chinese traditions and channels them towards Miramar's experience to create a newly imagined identity. 
Tools To Understand

Traditional Customs

Hybrid

Identity

Classical Novels

Oral Legends 


\section{Customs}

\section{Ancestry Is Important}

清明 (Qingming) Festival is a special day that celebrates deceased family members by cleaning the grave-sites and providing offerings to their ancestors as a way of remembrance.

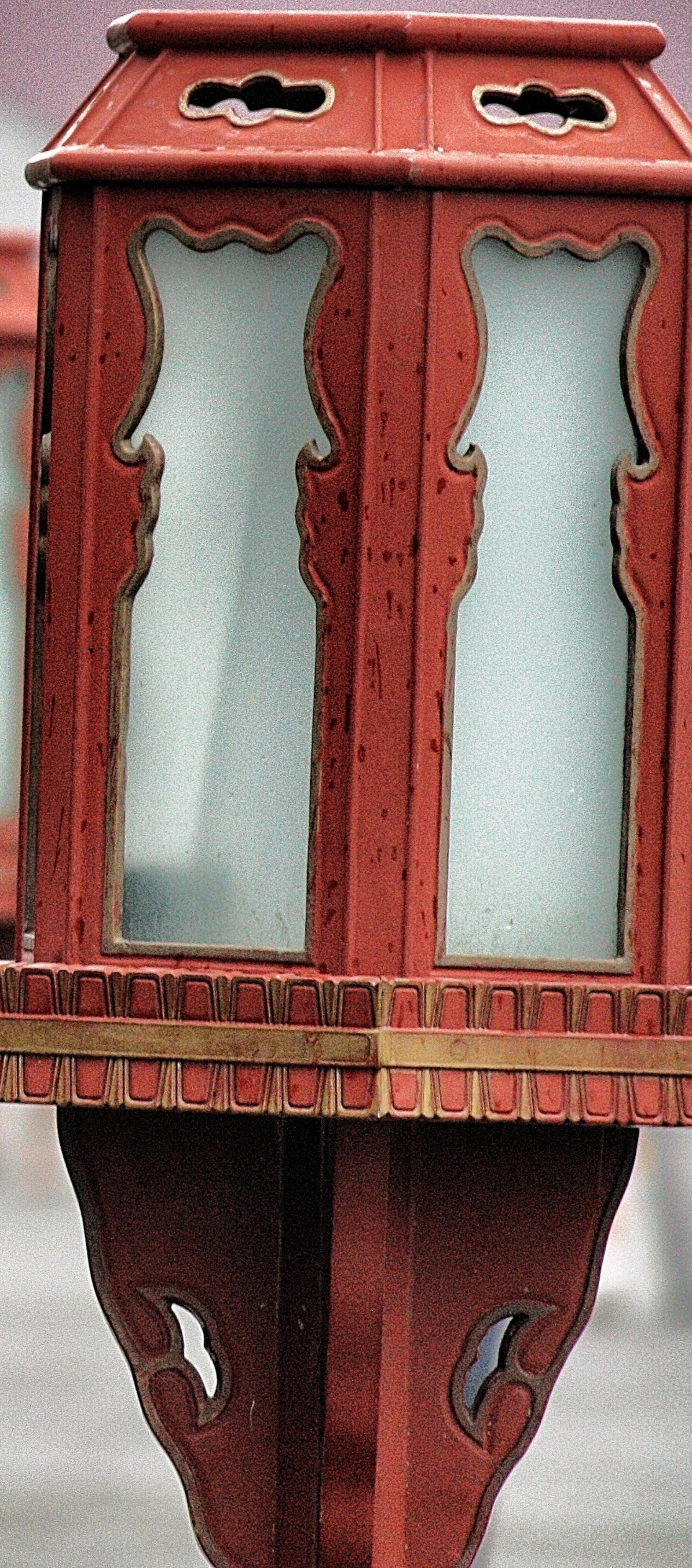




\section{Epigraph}

The ancestors rely on the living to keep up their quality of life. They knew that without the requisite incense, paper money, and roast duck once in a while, prepare to have back luck fall on your heads! The ancestors will curse you and suck their teeth about the ungrateful dogs that were their children. They will look hungrily at the other dead people whose children burned offerings and always remembered to put out a dish of meats and a can of Coke at the altar. The worst thing you can do to The Dead is to forget them. (Leung 71)
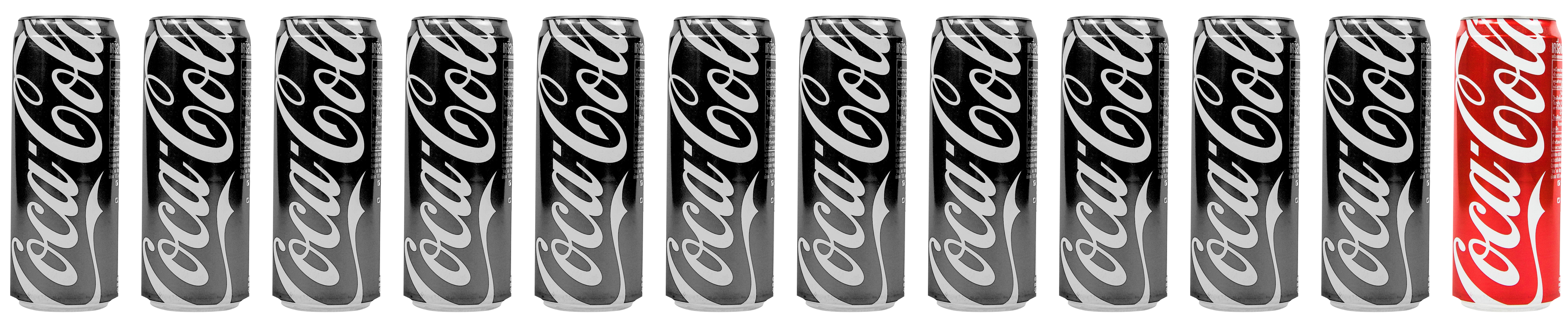


\section{Narrative}

Ma rejects the idea of visiting Ba's grave and prohibits the family from talking about their father.

"We do not talk about the dead on Chinese New Year."

"We will not talk about the dead" (75).

"I felt something intangible had just gotten lost and was irretrievable" (78).

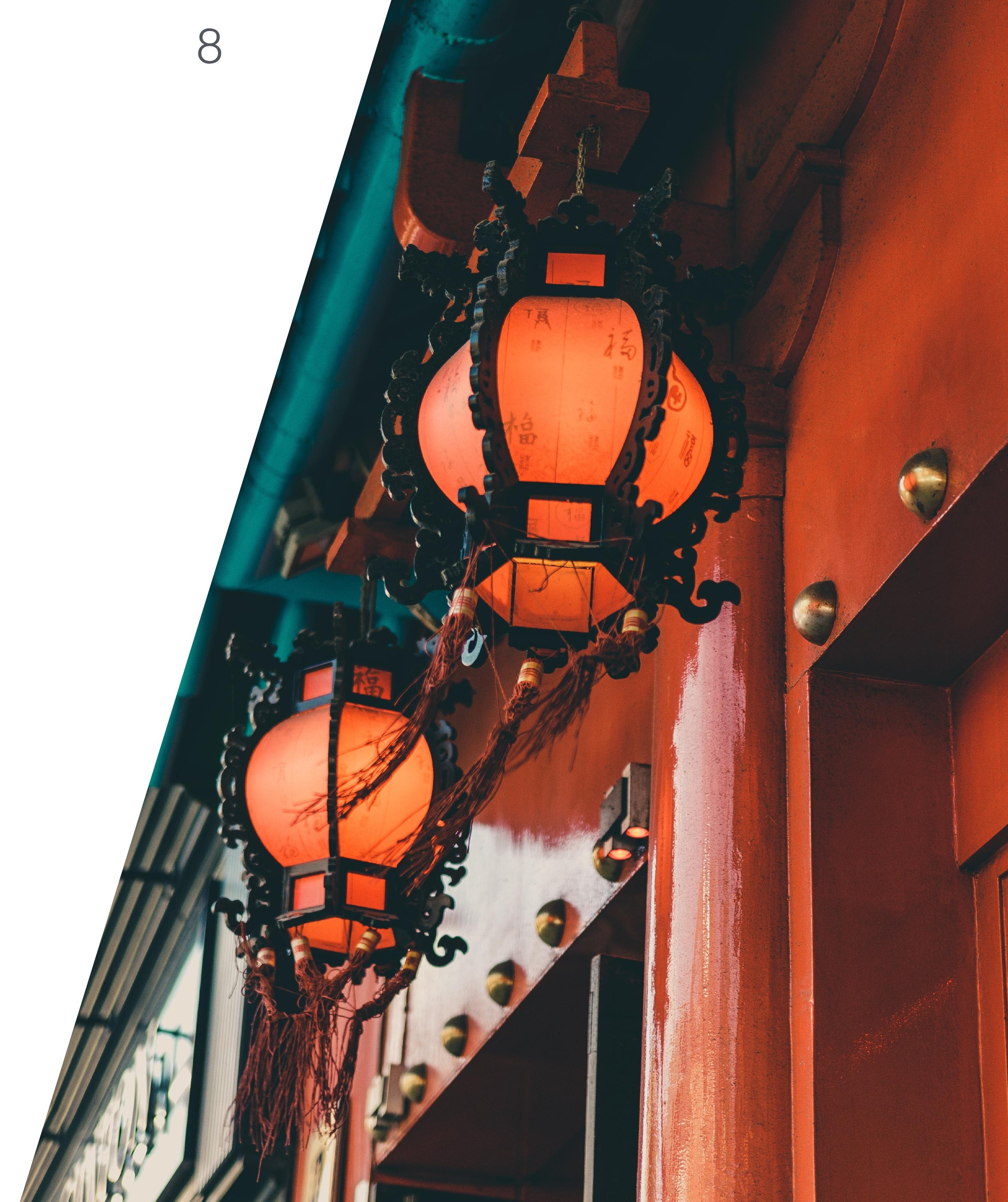


Nill Importance Of Ancestry Narrative

Expresses

Challenges Of Second Generation 


\section{Epigraph}

The Monkey King can be charming. But he has no loyalties to anyone but himself. Take care. He is capable of wreaking havoc in both heaven and earth. Or, at the very least, he could just be a player. (Leung 139)

Context: The Monkey King functions as an introduction for Mouse- - the love interest of Miramar-in the main narrative. 


\section{Narrative}

Player: A sexually successful person, usually a man; a playboy; (hence more generally) a successful, respected, or influential person (OED).

The Monkey King was never a "player" because he never took interest in sexual relationships.

Mouse repeatedly flirts with Miramar by calling her a "lang lui" meaning beautiful girl as a form of flattery. 
(c) Classical

in Characters

Significance

IIII Basic Foundation Identity 


\section{Oral Legends}

白 The Legend of the White Snake is an oral legend passed down from generations often adapted into various mediums such as film, theatre, and other forms.

蛇

传 The allusion to an oral legend is significant because it is clear that oral stories are slightly different each time, however the essence of it does not change. 


\section{Epigraph}

The Snake Sisters were immortals who lived for thousands of years and protected humans from ill fate - one was Green, the other White. They stopped floods from destroying villages and grew herbs to heal those who suffered from plague. They also mastered slipping into human form, passing as beautiful women who had suitors up the wazoo. Green Snake was the bold one who thirsted for adventure. She saw humans only as her playthings. White Snake respected mortals and fell in love with a scholar until Green Snake blew her cover and scared him to death by mistakenly revealing her reptilian self. This began a thousand-year feud. (Leung 86) 


\section{Narrative}

The original story is different from the epigraph, but it captured

the core element which is the close relationship between the snake sisters.

Original

Fahai exposed the

White Snake's Identity
Epigraph

Green Snake exposed the White Snake's identity which began a 1000 year feud

"The fragile thread that had always kept us tied to one other seemed frayed and the ends tangled." (Leung 93) 
S Fluid Oral Legend

패1내 Make Connections Identity 


\section{Final Epigraph}

"Yes, but Ba, I think the women were also out there -in the battle fields, in the woods, in the hills. The women had quests too. But they came home because they wanted their families to be together." (Leung 218)

Referring to her own family is significant because Miramar does not use allusions to traditional Chinese ideas, but rather she refers to herself in creating a new identity. 


\section{So What?}

1. Hybrid identities are not assimilated or altered independently

2. Combines traditions with present to create a hybrid identity 


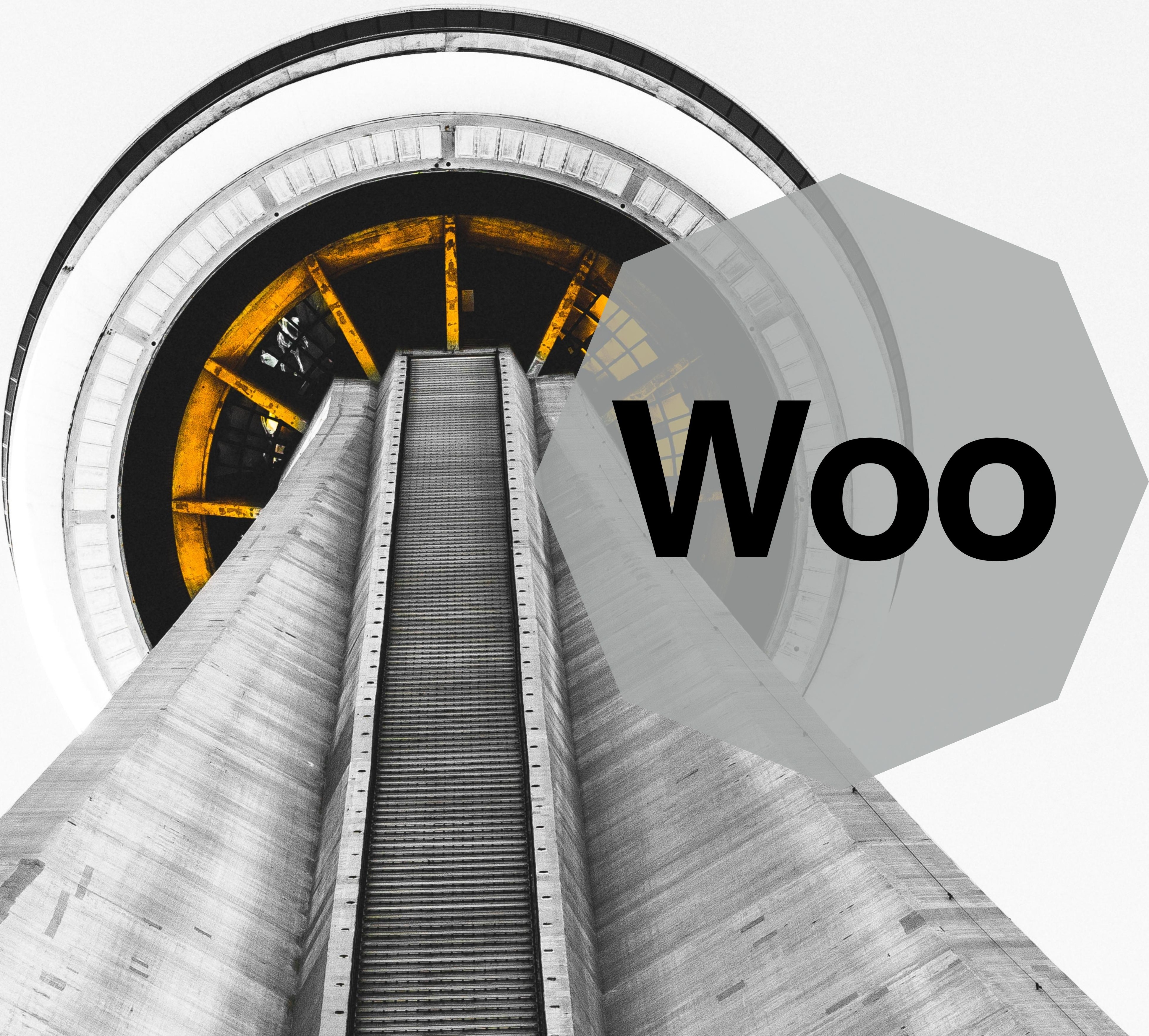

